\title{
BMR
}

\section{Association between $R N F 41$ gene c.-206 T $>$ A genetic polymorphism and risk of congenital heart diseases in the Chinese Mongolian population}

Y. Zhang ${ }^{1,2 *}$, S.Q. Jin ${ }^{3 *}$, W.X. Li ${ }^{4}$, G.Q. Gao ${ }^{5}$, K. Zhang ${ }^{1}$ and J.L. Huang ${ }^{2}$

${ }^{1}$ Department of Pathophysiology, Baotou Medical College, Baotou, China ${ }^{2}$ The Central Laboratory, Shenzhen Second People's Hospital, Shenzhen University First Affiliated Hospital, Shenzhen, China ${ }^{3}$ Department of Cardiology, The First Affiliated Hospital of Baotou Medical College, Baotou, China ${ }^{4}$ Department of Pediatric Cardiology, Beijing Anzhen Hospital Affiliated the Capital Medical University, Beijing, China ${ }^{5}$ Department of Emergency, The Central Hospital of Wulanchabu City, Wulanchabu, China

*These authors contributed equally to this study. Corresponding author: Y. Zhang

E-mail: susanyuan821@163.com

Genet. Mol. Res. 15 (2): gmr.15028089

Received November 18, 2015

Accepted January 18, 2016

Published June 17, 2016

DOI http://dx.doi.org/10.4238/gmr.15028089

ABSTRACT. This study aimed to explore the association between ring finger protein 41 (RNF41) c.-206 $\mathrm{T}>\mathrm{A}$ variant and susceptibility to congenital heart disease (CHD) in the Chinese Mongolian population. The association between $R N F 41$ gene c.-206 $\mathrm{T}>\mathrm{A}$ polymorphism and CHD was examined in two independent case-control studies consisting of 219 CHD patients and 208 healthy controls. Genotype was determined by direct sequencing of PCR products. We found that the genotype frequencies of RNF41 c.-206 T > A differ significantly 
between the two groups $(\mathrm{P}<0.05)$. The TT and TA genotypes in the CHD group were 80.67 and $19.33 \%$, respectively. On the other hand, the frequencies of TT and TA in the control group were 94.44 and 5.56\%, respectively. Furthermore, the allelic frequencies of CHD patients (T, $90.34 \%$; A, 9.66\%) were significantly different as compared with those of non-CHD controls (T, 97.22\%; A, 2.78\%; $\chi^{2}=4.031, \mathrm{P}=0.041$ ). Our study demonstrates that the RNF41 c.-206 T > A polymorphism may be a risk factor for congenital heart disease in the Chinese Mongolian population.

Key words: Congenital heart diseases; E3 ubiquitin ligase; Genetic variant; RNF41; Mongolian

\section{INTRODUCTION}

Congenital heart disease (CHD) is one of the most common birth defects, and accounts for approximately $28 \%$ of the major congenital birth defects. It is generally agreed that the occurrence of CHD is due to complex interactions between environmental and genetic factors, but the latter plays a more important role in the development of CHD (van der Linde et al., 2011). RNF41 is a RING finger-type E3 ubiquitin ligase, which belongs to the family of RING finger-containing proteins. It is primarily expressed in the heart, skeletal muscle, and brain (Abdullah et al., 2001). RNF41 has been reported to be involved in growth regulation, tumor suppression, and inflammatory responses by promoting the ubiquitination of several proteins such as ErbB3, BRUCE/apollon, and MyD88 (Qiu and Goldberg, 2002; Qiu et al., 2004; Wang et al., 2009). We have previously shown that overexpression of RNF41 in the heart tissue induced rapid inactivation of cardiac ErbB3, elevated myocardial apoptosis, inflammation, as well as tissue infarction in a rat model of heart $\mathrm{I} / \mathrm{R}$ injury (Zhang et al., 2011). RNF41 has been shown to interact with ErbB3, and down regulate its expression via proteasome-mediated degradation (Yen et al., 2006; Chen et al., 2010). Targeted deletion of ErbB receptors is embryonically lethal due to cardiovascular defects (Fuller et al., 2008). For example, ErbB3- null mice exhibit hypoplastic endocardial cushions, and often die during mid-gestation (Riethmacher et al., 1997). It is therefore possible that RNF41 may play a role in cardiac pathology, however, the exact mechanism by which RNF41 contributes to the pathogenesis of CHD remains elusive. In this study, we investigated the association between RNF41 polymorphisms and CHD in the Chinese Mongolian population.

\section{MATERIAL AND METHODS}

\section{Study population}

This study was approved by the Capital Medical University Beijing Anzhen Hospital and the Baotou Medical College Ethics Committee. Clinical and laboratory data were obtained, and informed consent was given by all subjects prior to peripheral blood sample collection. CHD patients (123 males, 96 females) were recruited between June 2007 and December 2014 from the Department of Pediatric Cardiology, Beijing Anzhen Hospital. All patients were of Chinese Mongolian descent originating from the Inner Mongolia autonomous region. Clinical details of the patients are summarized in Table 1. CHD was confirmed by color Doppler 
ultrasound or magnetic resonance imaging. A total of 208 non-CHD controls (119 males, 89 females) were recruited from the First Affiliated Hospital of Baotou Medical College, and were frequency-matched to CHD patients by gender and age. None of the control subjects had family history of CHD or other syndromes, and all were unrelated. Informed consent was obtained from all subjects.

Table 1. Clinical summary of CHD patients and non-CHD control subjects.
\begin{tabular}{l|c|c}
\hline & CHD & non-CHD \\
\hline Number of subjects & 219 & 208 \\
\hline Male (\%) & $123(56.30)$ & $119(57.40)$ \\
\hline Current age (years) & $2.15 \pm 1.23$ & $2.44 \pm 1.69$ \\
\hline Height (cm) & $86.48 \pm 7.53$ & $89.32 \pm 6.49$ \\
\hline Weight (kg) & $11.86 \pm 2.14$ & $12.71 \pm 2.72$ \\
\hline Pulse (rpm) & $118 \pm 9.83$ & $116 \pm 8.87$ \\
\hline Respiratory frequency (rpm) & $28 \pm 5.23$ & $26 \pm 4.17$ \\
\hline Blood pressure (systolic/diastolic, $\mathrm{mmHg})$ & & \\
\hline Left upper limb & $91 / 57$ & $92 / 56$ \\
\hline Right upper limb & $91 / 58$ & $91 / 59$ \\
\hline Left lower limb & $106 / 67$ & $109 / 71$ \\
\hline Right lower limb & $107 / 66$ & \\
\hline Complications (N, \%) & & \\
\hline Pneumonia & $41(34.45)$ & \\
\hline Heart failure & $3(2.52)$ & \\
\hline Aneurysm (N, \%) & $39(32.77)$ & \\
\hline VSD size (mm) & $8.54 \pm 1.27$ & \\
\hline
\end{tabular}

\section{Genotyping}

Blood ( $2 \mathrm{~mL}$ ) was drawn into EDTA-containing tubes, and white blood cells were isolated via centrifugation at $4000 \mathrm{rpm} / \mathrm{min}$ for $10 \mathrm{~min}$. Genomic DNA was extracted using the DNA Extraction Kit from Qiagen (Hilden, Germany). The human RNF41 gene (GenBank accession No. NM_005785) was amplified with specific primers designed using the Primer Premier 6.0 software (Premier Biosoft International, Palo Alto, CA, USA). PCRs were performed in a $20-\mu \mathrm{L}$ reaction mixture containing 50 ng template DNA, $100 \mathrm{nM}$ Tris- $\mathrm{HCl}(\mathrm{pH} 8.3), 500 \mathrm{mM} \mathrm{KCl}, 0.25 \mathrm{mM}$ primers, $2.0 \mathrm{mM} \mathrm{MgCl}_{2}, 0.25 \mathrm{mM}$ dNTPs (Bioteke Corporation, Beijing, China), and 0.5 U Taq DNA polymerase (Promega, Madison, WI, USA). The PCR amplification protocol was as follows: initial denaturation at $94^{\circ} \mathrm{C}$ for $5 \mathrm{~min}$, followed by 30 cycles of $94^{\circ} \mathrm{C}$ for $30 \mathrm{~s}, 58.5^{\circ} \mathrm{C}$ for $32 \mathrm{~s}, 72^{\circ} \mathrm{C}$ for 35 $\mathrm{s}$, and final extension was carried out at $72^{\circ} \mathrm{C}$ for $5 \mathrm{~min}$. The genotypes of $R N F 41 \mathrm{c}$.206T > A were investigated via DNA sequencing (ABI3730xl DNA Analyzer, Applied Biosystems, Foster City, CA, USA).

\section{Statistical analysis}

Statistical analyses were conducted using the SPSS 15.0 statistical software. HardyWeinberg equilibrium for the c.-206 T > A RNF41 variants were analyzed, and $\mathrm{c}^{2}$ tests were performed to compare the allelic and genotypic distributions between patients and controls. $\mathrm{P}$ $<0.05$ was considered statistically significant. 


\section{RESULTS}

\section{General characteristics}

The CHD patients were adequately matched for with non-CHD controls by gender and age, as suggested by $\chi^{2}$ tests $\left(\chi^{2}=1.9158, \mathrm{P}=0.1934\right.$ for gender; $\chi^{2}=1.9571, \mathrm{P}=0.1628$ for age). The mean age of CHD patients was comparable to that of non-CHD controls (2.15 \pm 1.23 vs $2.44 \pm 1.69)$.

\section{Analysis of RNF41 gene polymorphism}

We analyzed the allelic and genotypic distributions of c.-206 T > A polymorphism in all 219 CHD patients and 208 non-CHD controls. Sequence analyses suggested that this genetic polymorphism was a non-synonymous mutation resulting from a $\mathrm{T}$ to $\mathrm{A}$ transition in exon 2 of the RNF41 gene. Table 2 summarizes all allelic and genotypic frequencies in the studied populations. The allelic frequencies of CHD patients (T, 90.41\%; A, 9.59\%) differed significantly from that of non-CHD controls (T, 97.12\%; A, 2.88\%; $\chi^{2}=4.031, \mathrm{P}=0.041$, Table 2). The genotypic frequencies of CHD patients (TT, 80.82\%; TA, 19.18\%) were also different from that of non-CHD controls (TT, 94.23\%; TA, 5.77\%; $\chi^{2}=7.726, \mathrm{P}=0.009$, Table 2). In both CHD subjects and non-CHD controls, the genotypic distributions of the c.-206 T > A polymorphism were in Hardy-Weinberg equilibrium.

Table 2. Allelic and genotypic distribution frequencies for c.-206 T > A genetic polymorphism of RNF41 gene
in the CHD patients and non-CHD control subjects.
\begin{tabular}{|l|c|c|c|c}
\hline Allele or genotype & CHD [N (\%)] & non-CHD [N $(\%)]$ & $\chi^{2}$ & P value \\
\hline Allele A & $42(9.59 \%)$ & $12(2.88 \%)$ & & \\
\hline Allele T & $396(90.41 \%)$ & $404(97.12 \%)$ & 4.031 & 0.041 \\
\hline Genotype TA & $42(19.18 \%)$ & $12(5.77 \%)$ & & \\
\hline Genotype TT & $177(80.82 \%)$ & $196(94.23 \%)$ & 7.726 & 0.009 \\
\hline
\end{tabular}

Genotypic and allelic data are reported as number with percent in parentheses, respectively. The $\chi^{2}$ tests were used for statistical analyses.

\section{DISCUSSION}

In this study, we examined whether sequence variations in the RNF41 gene contribute to CHD development. In the cardiovascular research, more focus has been placed on finding genes that are activated during pathogenesis of heart diseases. However, the removal of damaged proteins and organelles has been underappreciated in this field. Cardiac proteotoxicity has been increasingly recognized as an important contributor to the development of various congenital and acquired human heart diseases (Sandri and Robbins, 2014). The ubiquitinproteasome system (UPS) is involved in the maintenance of protein homeostasis (Egeler et al., 2011; Schlossarek et al., 2014). Impairment of the UPS is characterized by reduced levels of ubiquitinated proteins and proteasome activities, which has been reported in inherited cardiomyopathies. Altered UPS activity may contribute to cardiac dysfunction due to dysregulated turnover of cardiac proteins, changes in transcriptional activation of stress response proteins, reduced degradation of damaged proteins, and onset of stress responses (Weekes et al., 2003; Sarikas et al., 2005; Vang et al., 2005; Liu et al., 2006; Patterson et 
al., 2007; Rajasekaran et al., 2007). The ubiquitin ligases UBR1 and UBR2 appear to be indistinguishable in their recognition of N-degrons, and are essential for proper cardiac development. Studies showed that knockdown of UBR1 and UBR2 resulted in a wide range of cardiovascular abnormalities in mice (Kwon et al., 2003; Varshavsky, 2004). In addition, mutation analysis in regions of homozygosity identified a conserved homozygous missense mutation in the TRIM32 gene. TRIM32 also encodes for an E3 ubiquitin ligase, and mutations in this gene contributes to cardiac abnormalities (Chiang et al., 2006).

RNF41 is an E3 ligase that dictates the spatial, temporal, and substrate specificity of ubiquitination. It promotes the ubiquination of ErbB3, BRUCE/apollon, TBK1, Parkin, and $\mathrm{C} / \mathrm{EBP} \beta$, thereby regulating cell growth, apoptosis, and inflammation (Qiu and Goldberg, 2002; Qiu et al., 2004; Yu and Zhou, 2008; Wang et al., 2009; Ingalla et al., 2010; Tan et al., 2011; Zhou et al., 2011; Ye et al., 2012). Accumulating evidence suggests that RNF41 plays an important role in heart diseases. The E3 ubiquitin ligase $R N F 41$ has been shown to interact with the N terminal of ErbB3, and catalyzed degradation of ErbB3 via the ubiquitin-proteasome pathway (Qiu and Goldberg, 2002). Our previous study showed that RNF41 mediated ErbB3 protein degradation to augment ischemia/reperfusion heart injury (Zhang et al., 2011).

The ErbB receptor tyrosine kinase family is comprised of 4 members, namely EGFR (ErbB1), ErbB2, ErbB3, and ErbB4. Gene targeting strategies in mice have highlighted the significance of the ErbB receptors in cardiac function and development (Chen et al., 2010). Cardiac-specific ErbB2-knockout mice were able to survive to adulthood, but showed dilated cardiomyopathy at 3 months of age. Mice lacking the ErbB4 gene die during midembryogenesis from aborted development of the myocardial trabeculae in heart ventricles (Chen et al., 2010). More importantly, ErbB3-null mice often die during mid-gestation due to the presence of hypoplastic endocardial cushions. Recent studies have reported that RNF41 specifically binds to ErbB3 to induce proteasome-dependent degradation of ErbB3 and cell death (Yen et al., 2006; Cao et al., 2007), suggesting that RNF41 may contribute to heart development via regulation of ErbB3 expression.

Mo et al. (2010) identified two genetic variations (c.-206 T > A and c.-208-8 A > $\mathrm{G})$ in the Han Chinese population with and without Parkinson disease. The c.-206 T > A polymorphism was identified in $6.52 \%$ of the 302 controls, but c.-208-8 A $>$ G was not found in those subjects. However, they failed to show a positive association between c.-206 T > A polymorphism and Parkinson disease. Considering the influence of genetic heterogeneity, the contribution of RNF41 to the pathogenesis of disease may be markedly influenced by ethnic background and geographic origin of the patients. It is therefore necessary to screen mutations in RNF41 in other ethnic populations. Since c.-206 T > A is located in exon 2 of the RNF41 gene, we investigate the potential association between c.-206 $\mathrm{T}>\mathrm{A}$ genetic polymorphism in the RNF41 gene and risk of CHD. Our findings indicated that allele-A and genotype-TA may be associated with increased risk for CHD. Our results suggested that the allelic and genotypic frequencies of RNF41 gene c.-206 T > A polymorphism are associated with CHD in the Mongolian Chinese population.

In summary, to the best of our knowledge, this study was the first to evaluate the genetic variants of the RNF41 gene. We found that variant c.-206 T > A polymorphism was significantly associated with risk of CHD in the Chinese Mongolian population. Therefore, it may be a potential molecular biomarker for evaluating CHD risk. Our results accentuated the importance of E3 ligase during embryo heart development. This study provided new insights for risk assessments of common birth defects, and shed some light on the roles of genetics 
and ethnic backgrounds in congenital heart diseases. Future studies should aim to determine whether RNF41 is involved the degradation of ErbB3 or other substrates via the ubiquitinproteasome pathway in CHD patients.

\section{Conflicts of interest}

The authors declare no conflicts of interest.

\section{ACKNOWLEDGMENTS}

Research supported by grants from the China Natural Science Foundation (\#81200124), the Program for Young Talents of Science and Technology in Universities of Inner Mongolia Autonomous Region (\#NJYT-13-B19), and the Program for Young Innovation Talents of Baotou city.

\section{REFERENCES}

Abdullah JM, Li X, Nachtman RG and Jurecic R (2001). FLRF, a novel evolutionarily conserved RING finger gene, is differentially expressed in mouse fetal and adult hematopoietic stem cells and progenitors. Blood Cells Mol. Dis. 27: 320-333. http://dx.doi.org/10.1006/bcmd.2001.0390

Cao Z, Wu X, Yen L, Sweeney C, et al. (2007). Neuregulin-induced ErbB3 downregulation is mediated by a protein stability cascade involving the E3 ubiquitin ligase Nrdp1. Mol. Cell. Biol. 27: 2180-2188. http://dx.doi.org/10.1128/ MCB.01245-06

Chen L, Siddiqui S, Bose S, Mooso B, et al. (2010). Nrdp1-mediated regulation of ErbB3 expression by the androgen receptor in androgen-dependent but not castrate-resistant prostate cancer cells. Cancer Res. 70: 5994-6003. http:// dx.doi.org/10.1158/0008-5472.CAN-09-4440

Chiang AP, Beck JS, Yen HJ, Tayeh MK, et al. (2006). Homozygosity mapping with SNP arrays identifies TRIM32, an E3 ubiquitin ligase, as a Bardet-Biedl syndrome gene (BBS11). Proc. Natl. Acad. Sci. USA 103: 6287-6292. http:// dx.doi.org/10.1073/pnas. 0600158103

Egeler EL, Urner LM, Rakhit R, Liu CW, et al. (2011). Ligand-switchable substrates for a ubiquitin-proteasome system. J. Biol. Chem. 286: 31328-31336.http://dx.doi.org/10.1074/jbc.M111.264101

Fuller SJ, Sivarajah K and Sugden PH (2008). ErbB receptors, their ligands, and the consequences of their activation and inhibition in the myocardium. J. Mol. Cell. Cardiol. 44: 831-854.http://dx.doi.org/10.1016/j.yjmcc.2008.02.278

Ingalla EQ, Miller JK, Wald JH, Workman HC, et al. (2010). Post-transcriptional mechanisms contribute to the suppression of the ErbB3 negative regulator protein Nrdp1 in mammary tumors. J. Biol. Chem. 285: 28691-28697. http://dx.doi. org/10.1074/jbc.M110.127977

Kwon YT, Xia Z, An JY, Tasaki T, et al. (2003). Female lethality and apoptosis of spermatocytes in mice lacking the UBR2 ubiquitin ligase of the N-end rule pathway. Mol. Cell. Biol. 23: 8255-8271. http://dx.doi.org/10.1128/ MCB.23.22.8255-8271.2003

Liu J, Chen Q, Huang W, Horak KM, et al. (2006). Impairment of the ubiquitin-proteasome system in desminopathy mouse hearts. FASEB J. 20: 362-364.

Mo X, Liu D, Li W, Hu Z, et al. (2010). Genetic screening for mutations in the Nrdp1 gene in Parkinson disease patients in a Chinese population. Parkinsonism Relat. Disord. 16: 222-224.http://dx.doi.org/10.1016/j.parkreldis.2009.09.001

Patterson C, Ike C, Willis PW, 4th, Stouffer GA, et al. (2007). The bitter end: the ubiquitin-proteasome system and cardiac dysfunction. Circulation 115: 1456-1463. http://dx.doi.org/10.1161/CIRCULATIONAHA.106.649863

Qiu XB and Goldberg AL (2002). Nrdp1/FLRF is a ubiquitin ligase promoting ubiquitination and degradation of the epidermal growth factor receptor family member, ErbB3. Proc. Natl. Acad. Sci. USA 99: 14843-14848. http://dx.doi. org/10.1073/pnas.232580999

Qiu XB, Markant SL, Yuan J and Goldberg AL (2004). Nrdp1-mediated degradation of the gigantic IAP, BRUCE, is a novel pathway for triggering apoptosis. EMBO J. 23: 800-810.http://dx.doi.org/10.1038/sj.emboj.7600075

Rajasekaran NS, Connell P, Christians ES, Yan LJ, et al. (2007). Human alpha B-crystallin mutation causes oxidoreductive stress and protein aggregation cardiomyopathy in mice. Cell 130: 427-439. http://dx.doi.org/10.1016/j. cell.2007.06.044 
Riethmacher D, Sonnenberg-Riethmacher E, Brinkmann V, Yamaai T, et al. (1997). Severe neuropathies in mice with targeted mutations in the ErbB3 receptor. Nature 389: 725-730.http://dx.doi.org/10.1038/39593

Sandri M and Robbins J (2014). Proteotoxicity: an underappreciated pathology in cardiac disease. J. Mol. Cell. Cardiol. 71: 3-10.http://dx.doi.org/10.1016/j.yjmcc.2013.12.015

Sarikas A, Carrier L, Schenke C, Doll D, et al. (2005). Impairment of the ubiquitin-proteasome system by truncated cardiac myosin binding protein C mutants. Cardiovasc. Res. 66: 33-44. http://dx.doi.org/10.1016/j.cardiores.2005.01.004

Schlossarek S, Frey N and Carrier L (2014). Ubiquitin-proteasome system and hereditary cardiomyopathies. J. Mol. Cell. Cardiol. 71: 25-31.http://dx.doi.org/10.1016/j.yjmcc.2013.12.016

Tan Y, Yu F, Pereira A, Morin P, et al. (2011). Suppression of Nrdp1 toxicity by Parkin in Drosophila models. Biochem. Biophys. Res. Commun. 416: 18-23.http://dx.doi.org/10.1016/j.bbrc.2011.10.104

van der Linde D, Konings EE, Slager MA, Witsenburg M, et al. (2011). Birth prevalence of congenital heart disease worldwide: a systematic review and meta-analysis. J. Am. Coll. Cardiol. 58: 2241-2247. http://dx.doi.org/10.1016/j. jacc.2011.08.025

Vang S, Corydon TJ, Børglum AD, Scott MD, et al. (2005). Actin mutations in hypertrophic and dilated cardiomyopathy cause inefficient protein folding and perturbed filament formation. FEBSJ. 272: 2037-2049. http://dx.doi.org/10.1111/ j.1742-4658.2005.04630.x

Varshavsky A (2004). 'Spalog' and 'sequelog': neutral terms for spatial and sequence similarity. Curr. Biol. 14: R181-R183. http://dx.doi.org/10.1016/j.cub.2004.02.014

Wang C, Chen T, Zhang J, Yang M, et al. (2009). The E3 ubiquitin ligase Nrdp1 'preferentially' promotes TLR-mediated production of type I interferon. Nat. Immunol. 10: 744-752. http://dx.doi.org/10.1038/ni.1742

Weekes J, Morrison K, Mullen A, Wait R, et al. (2003). Hyperubiquitination of proteins in dilated cardiomyopathy. Proteomics 3: 208-216. http://dx.doi.org/10.1002/pmic.200390029

Ye S, Xu H, Jin J, Yang M, et al. (2012). The E3 ubiquitin ligase neuregulin receptor degradation protein 1 (Nrdp1) promotes M2 macrophage polarization by ubiquitinating and activating transcription factor CCAAT/enhancerbinding Protein $\beta$ (C/EBP $\beta)$. J. Biol. Chem. 287: 26740-26748. http://dx.doi.org/10.1074/jbc.M112.383265

Yen L, Cao Z, Wu X, Ingalla ER, et al. (2006). Loss of Nrdp1 enhances ErbB2/ErbB3-dependent breast tumor cell growth. Cancer Res. 66: 11279-11286. http://dx.doi.org/10.1158/0008-5472.CAN-06-2319

Yu F and Zhou J (2008). Parkin is ubiquitinated by Nrdp1 and abrogates Nrdp1-induced oxidative stress. Neurosci. Lett. 440: 4-8.http://dx.doi.org/10.1016/j.neulet.2008.05.052

Zhang Y, Zeng Y, Wang M, Tian C, et al. (2011). Cardiac-specific overexpression of E3 ligase Nrdp1 increases ischemia and reperfusion-induced cardiac injury. Basic Res. Cardiol. 106: 371-383.http://dx.doi.org/10.1007/s00395-011-0157-0

Zhou A, Pan D, Yang X and Zhou J (2011). Overexpression of Nrdp1/FLRF sensitizes cells to oxidative stress. Biochem. Biophys. Res. Commun. 410: 771-774.http://dx.doi.org/10.1016/j.bbrc.2011.06.052 